\title{
Tabellen verzeichniss.
}

Ni. 45. Glieder der Pentamethylengruppe :

Nr. 46. Glieder der Heptamethylengruppe. . . . . : . . . . . . . 39

Nr. 47. Benzolkohlenwasserstoffe . . . . . . . . . . . . . . . . 102

Nr. 48. Bromderivate der Benzolkohlenwasserstotie . . . . . . . . . 120

Nr. 49. Sulfosăuren der Benzolkohlenwasserstoffe . . . . . . . . . . . 135

Nr. 50. Nitroderivate der Benzolkohlenwasserstoffe . . . . $\quad$. . . 154

Nr. 51. Substitutionsprodukte des Anilins . . . . . . . . . . . . . 207

Nr. 52. Homologe des Anilins . . . . . . . . . . . . . . . . . . 223

Nr. 53. Derivate der Toluidine . . . . . . . . . . . . . . 226

Nr. 54. Azokohlenwasserstoffe . . . . . . . . . . . . . . . 257

Nr. 55. Einwerthige Pbenole . . . . . . . . . . . . . . . . . 368

Nr. 56. Substitutionsprodukte des Phenols . . . . . . . . . . . . . 382

Nr. 57. Chinone und ihre Derivate . . . . . . . . . . . . . . . . 445

Nr. 58. Aromatische Aldehyde . . . . . . . . . . . . . . . . . 484

Nr. 59. Fettaromatigclie Kntouc . . . . . . . . . . . . . . . . . 493

Nr. 60. Methylhomologe der Benzoëgäure . . . . . . . . . . . . . . 539

Nr. 61. Benzočgăure-Derivate . . . . . . . . . . . . . . . . . . 548

Nr. 62. Substituirte Benzoësäuren . . . . . . . . . . . . . . . . 566

Nr. 63. Derivate und Homologe der Kimmtsïure . . . . . . . . . . . 608

Nr. 64. Derivate und Humologe der Salicylsäure. . . . . . . . . . . . $\quad 633$

Nr. 65. Dioxybenzoësüuren . . . . . . . . . . . . . . . . . . . 640

Nr. 66. Cyclohexan-Kohlenwasgerstutfe . . . . . . . . . . . . . . . 786

Nr. 67. Kohlenwasserstotfe der Cyclohezen- und Cyclohexadiën-Reihe . . 801

Nr. 68. Einwerthige, gesattigte Alkohole der Hexsmethylengruppe . . . 804

Nr. 69. Gesättigte Monoketone der Hexamethylengruppe . . . . . . . . 814

Nr. 70. Ungesättigte Monoketone der Hexamethylengruppe . . . . . . . 830

Nr. 71. Zusammenhang der Hydroterephtalsüuren. . . . . . . . . . . . 874 